\title{
Sweet Sticky Rice Puree Diet for Elderly with Dysphagia
}

\author{
Paweerisa CHOICHUEDEE ${ }^{1}$, Uthaiwan SUTTISANSANEE ${ }^{2}$, \\ Chatrapa HUDTHAGOSOL ${ }^{1}$ and Promluck SANPORKHA, ${ }^{1, *}$
}

\author{
${ }^{1}$ Department of Nutrition, Faculty of Public Health, Mahidol University, Bangkok 10400, Thailand \\ ${ }^{2}$ Institute of Nutrition, Mahidol University, Nakhon Pathom 73170, Thailand
}

('Corresponding author's e-mail: promluck@yahoo.com)

Received: 30 May 2017, Revised: 7 May 2018, Accepted: 18 June 2018

\begin{abstract}
This research aimed to study the effect of xanthan gum $(X G)$ on physico-chemical and sensory properties of sweet sticky rice puree diet (SRD). The 3 different concentrations of XG at $0.75,1.00$, and $1.25 \%(\mathrm{w} / \mathrm{w})$ were added to SRD. The results showed that shear stress and shear rate $\left(50 \mathrm{~s}^{-1}\right)$ at $25^{\circ} \mathrm{C}$ of SRD with $0.75,1.00$, and $1.25 \%(\mathrm{w} / \mathrm{w})$ were fitted to the power law model with high determination coefficients $\left(R^{2}=0.94-0.97\right)$. All of the SRD samples showed high shear-thinning behavior $(\mathrm{n}=0.18$ 0.21 ), and the apparent viscosities were in the range of 5.13 to 7.07 Pa.s. Thus, all 3 SRD samples were classified as pureed diet. Sensory evaluation was conducted by 20 elderly people with dysphagia, who classified as an untrained panel. The results showed that texture, color, flavor, taste, and overall acceptability of SRD with different levels of XG were not significantly different $(p>0.05)$, but SRD with $0.75 \% \mathrm{XG}$ was selected to be further developed, because it was identified by the elderly people with dysphagia that it was the easiest to swallow puree diet. In addition, the total phenolic content and antioxidant activities by DPPH, FRAP, and ORAC assay of SRD with $0.75 \%$ XG were 29.52 mgGAE/100g, 45.16, 88.96, and $497.87 \mu \mathrm{mol} \mathrm{TE} / 100 \mathrm{~g}$, respectively. In conclusion, SRD could improve swallowing safety for the elderly with dysphagia and is able to be classified as a pureed diet following the standards of the National Dysphagia Diet.
\end{abstract}

Keywords: Sticky rice flour, puree diet, elderly, dysphagia

\section{Introduction}

Nowadays, the proportion of the elderly population in the world is steadily increasing. According to the statistics of the United Nations, the world's elderly population of 901 million in 2015 is projected to increase to 2.1 billion by 2030 [1], while the Thai elderly population will also increase, from 10.3 million in 2015 to 17.5 million by 2030 , representing 25 percent of Thailand's population [2,3]. Thai society will become a completely aged society. The aging process involves psychological, social, and, especially, physical changes, such as in the respiratory system, cardiovascular system, and gastrointestinal system, along with the mouth and teeth [4,5]. A 2013 survey on food consumption behaviors of Thai elderly showed that 60 percent had a problem with mastication, 56 percent had a problem with taste perception, and 26 percent had a problem with the swallowing and choking of food or liquid [6], resulting in dysphagia in the elderly.

Dysphagia is defined as difficulty in swallowing solids, liquids, or both, an important problem occurring in the elderly population. Changes in ability or function in swallowing increases the risk of swallowing disorder. This occurs with increasing age and is associated with age-related diseases and conditions [7]. These relate to a variety of negative health status changes, such as increased risk of malnutrition and pneumonia [8]. Thus, modified texture foods are necessary for the management of swallowing in the elderly with dysphagia [9]. The National Dysphagia Diet (NDD) classified the 
http://wjst.wu.ac.th

dysphagia diet into 4 categories, Dysphagia pureed (Level 1), Dysphagia mechanically altered (Level 2), Dysphagia advanced (Level 3), and Liquid consistency [10].

Xanthan gum (XG) is a natural polysaccharide produced by bacterium Xanthomonas campestris. The primary structure of XG consists of glucose, mannose, and glucuronic acid in a molar ratio of 2:2:1. The major applications of XG in the food industry are as stabilizers and thickeners in salad dressings, soups, gravies, desserts, toppings, and dairy products [11]. Furthermore, it is used in dysphagia management, because thickened food and drink changes the rate at which they are transported through the pharynx [12]. The important property of XG is its ability to produce high viscosity at low concentration. $\mathrm{XG}$ is soluble and disperses in hot or cold water. It is able to bind water, leading to very high viscosity solutions at low concentration. Its rheological behavior enables XG to contribute to good sensory qualities, including mouthfeel and flavor release in food [13]. XG solution is stable over a wide range of salt concentrations (up to $150 \mathrm{~g} / 1 \mathrm{NaCl}$ ), temperatures (up to $90{ }^{\circ} \mathrm{C}$ ), and $\mathrm{pH}(2-11)$ [14]. Moreover, it is interesting that $\mathrm{XG}$ shows the ability to react with free radicals, indicating a potential role as an antioxidative molecule [15].

The modified texture of SRD will be good choice for managing malnutrition and pneumonia in dysphagia. In addition, SRD will be a source of antioxidant compounds. Therefore, the objective of this research was to use XG to modify the texture of SRD. The effect of XG was investigated in terms of physio-chemical and sensory properties of SRD.

\section{Materials and methods}

\section{Preparation of sticky rice flour (SF)}

Sticky rice was purchased from Chiangrai Rice Research Center. The rice was milled by the dry milling method, using a grinder (Yong Horus Industry and Trade Co. Ltd., Yongkang, Zhejiang, China), and passed through a sieve with at a particle size of 80 mesh screen. SF was packed in polyethylene laminated with aluminum foil bags, vacuum-sealed, and stored at $-20{ }^{\circ} \mathrm{C}$ prior to analysis and used as a component in sweet sticky rice puree diet.

\section{Preparation of sweet sticky rice puree diet (SRD)}

SRD with different concentrations of XG $(0.75,1.00$, and $1.25 \%(\mathrm{w} / \mathrm{w}))$ were prepared by blending the dry ingredients (SF, egg white powder, sugar, salt, and $\mathrm{XG}$ ) into wet ingredients (coconut cream substitute and water); then, stirring until all ingredients were mixed well and preheating at $50{ }^{\circ} \mathrm{C}$ with hot steam, and, finally, pouring it into glass bottle and sterilizing it at $121{ }^{\circ} \mathrm{C}$ with a pressure of 15 psi for 15 min. The samples were stored in glass bottles, and then the 3 formulas of SRD were evaluated for rheological and sensory properties, total phenolic content, and antioxidant activities.

\section{Rheological measurement}

Rheological measurement was carried out with a controlled-stress rheometer (Thermo Fisher Scientific Inc., Waltham, Massachusetts, USA), using a serrated plate and plate geometry (35 $\mathrm{mm}$ diameter) at a gap of $1 \mathrm{~mm}$. Steady flow data were obtained over a shear rate range of 0.01 to $100 \mathrm{~s}^{-1}$ at 25 ${ }^{\circ} \mathrm{C}$. Data (shear stress and shear rate) were fitted to the power law model (Eq. (1)) to describe the flow properties of SRD;

$\sigma=\mathrm{K} \gamma^{\bullet \mathrm{n}}$

where $\sigma$ is the shear stress $(\mathrm{Pa}), \gamma^{\cdot}$ is the shear rate $\left(\mathrm{s}^{-1}\right), \mathrm{K}$ is the consistency index $\left(\mathrm{Pa} . \mathrm{s}^{\mathrm{n}}\right)$, and $\mathrm{n}$ is the flow behavior index (dimensionless). Apparent viscosity $\left(\eta_{\mathrm{a}, 50}\right)$ at $50 \mathrm{~s}^{-1}$, a reference shear rate for swallowing, was calculated using the magnitudes of $\mathrm{K}$ and $\mathrm{n}$. Rheological measurement was done in triplicate. 
http://wjst.wu.ac.th

\section{Sensory properties}

Ethical approval was given by the Center of Ethic Reinforcement for Human Research, Mahidol University. The sensory evaluation was conducted in Ban Bang Khae Social Welfare Development Center for Older Persons and Bangkok Special Nurse. The panelists, aged 60 years and older (20 percent males and 80 percent females), were recruited to participate in this study by using the original version of the dysphagia screening questionnaire [16]. The SRD samples were evaluated by 20 elderly panelists with dysphagia. The samples were prepared one day prior to the sensory day, and each sample was labeled with 3-digit random numbers and randomly served to each elderly panelist. Texture, color, flavor, taste, and overall acceptability were evaluated by using a 9 -point hedonic scale $(9=$ like extremely, $5=$ neither like nor dislike, 1 = dislike extremely). Difficulty in swallowing was evaluated by using a ranking scale.

\section{Determination of total phenolic content and antioxidant activities \\ Sample extraction}

SRD was extracted with $40 \%$ ethanol with a solvent to the sample ratio of 1:10 at room temperature by using a shaking water bath for $5 \mathrm{~h}$. The mixture was centrifuged at $5000 \times \mathrm{g}$ for $15 \mathrm{~min}$ at $25{ }^{\circ} \mathrm{C}$ and the supernatant was filtered through Whatman No. 1 filter paper. The supernatant was kept in amber glass bottles and stored at $4{ }^{\circ} \mathrm{C}$ until further analysis.

\section{Determination of total phenolic content}

The total phenolic content of each extract sample was determined using the Folin-Ciocalteu method, as modified by Amarowicz et al. [17]. The extracts $(25 \mu \mathrm{l})$ were reacted with $10 \%(\mathrm{v} / \mathrm{v})$ Folin-Ciocalteu reagent $(50 \mu \mathrm{l})$, after adding $7.5 \%(\mathrm{w} / \mathrm{v})$ sodium bicarbonate $(200 \mu \mathrm{l})$, and incubated in a dark room at $25 \pm 5{ }^{\circ} \mathrm{C}$ for $2 \mathrm{~h}$. The absorbance of the resulting solution was measured at $765 \mathrm{~nm}$. Gallic acid solutions $(10,20,40,60,80,100$, and $200 \mu \mathrm{g} / \mathrm{ml})$ were used as a standard, and deionized water was used as a blank. Total phenolic content was expressed as milligrams of gallic acid equivalent per $100 \mathrm{~g}$ of dry weight of sample. The experiments were carried out in triplicate.

\section{Determination of antioxidant activities}

\section{2,2-diphenyl-1-picrylhydrazyl radical scavenging activity (DPPH) assay}

The DPPH assay was determined according to the method as modified by Fukumoto and Mazza [18]. The extracts $(22 \mu \mathrm{l})$ were reacted with $200 \mu \mathrm{l}$ DPPH $(150 \mu \mathrm{M})$ solution and incubated in a dark room at $25 \pm 5{ }^{\circ} \mathrm{C}$ for $30 \mathrm{~min}$. The absorbance of the resulting solution was measured at $520 \mathrm{~nm}$. Trolox solutions $(0.01,0.02,0.04,0.08,0.16,0.32$, and $0.64 \mathrm{mM})$ were used as a standard, and $95 \%$ ethanol solution (v/v) was used as a blank. The DPPH radical scavenging activity was expressed as $\mu$ mole Trolox equivalent per $100 \mathrm{~g}$ of dry weight of sample. The experiments were carried out in triplicate.

\section{Ferric reducing antioxidant power (FRAP) assay}

The FRAP assay was determined according to the method as modified by Benzie and Strainin [19]. The extracts $(20 \mu \mathrm{l})$ were reacted with FRAP reagent $(150 \mu \mathrm{l})$ and incubated in a dark room at $25 \pm 5{ }^{\circ} \mathrm{C}$ for $8 \mathrm{~min}$. The absorbance of the resulting solution was measured at $600 \mathrm{~nm}$. Trolox solution $(6.25,12.5$, $25,50,100,200$, and $400 \mu \mathrm{M})$ was used as a standard, and deionized water was used as a blank. The FRAP values were expressed as $\mu$ mole Trolox equivalent per $100 \mathrm{~g}$ of dry weight of sample. The experiments were carried out in triplicate.

\section{Oxygen radical absorbance capacity (ORAC) assay}

The ORAC assay was determined according to the method as explained by $\mathrm{Ou}$ et al. [20]. The extracts $(25 \mu \mathrm{l})$ were reacted with fluorescence solution $(30 \mathrm{mM})$ and incubated at $37{ }^{\circ} \mathrm{C}$ for $15 \mathrm{~min}$. After the incubation, 2, 2' -azobis (2-amidinopropane) dihydrochloride (AAPH) was added to the reaction mixture and the reaction immediately started. The fluorescence intensity was monitored for 90 min by using a microplate reader (Synergy HT multi-detection microplate reader, Bio-Tex Instruments, Inc., Winooski, U.S.A.), with an excitation wavelength of $485 \mathrm{~nm}$ and an emission wavelength of $528 \mathrm{~nm}$. 
http://wjst.wu.ac.th

Trolox solutions $(3.125,6.25,12.5,25,50$, and $100 \mu \mathrm{M})$ were used as a standard, and ORAC buffer working solution was used as a blank. The final ORAC values were calculated using the differences of area under the fluorescence decay curve (AUC) between the blank and the sample. The area under the fluorescence decay curve (AUC) was calculated according to the following equation;

$\mathrm{AUC}=0.5+f_{1} / f_{0}+f_{\mathrm{i} /} f_{0}+\ldots+f_{89} / f_{0}+0.5\left(f_{90} / f_{0}\right)$

where $f_{0}=$ initial fluorescence reading at $0 \min$ and $f_{\mathrm{i}}=$ fluorescence reading at time $\mathrm{i} \min$. Final ORAC values were calculated as follows, and expressed as $\mu$ mole Trolox equivalent per $100 \mathrm{~g}$ of dry weight of sample;

ORAC value $=\left[\left(\mathrm{AUC}_{\text {sample }}-\mathrm{AUC}_{\text {blank }}\right) /\left(\mathrm{AUC}_{\text {trolox }}-\mathrm{AUC}_{\text {blank }}\right) \times\right.$ dilution $]$

\section{Results and discussion}

\section{Rheological measurement}

The SRD samples were homogenous, cohesive, of smooth texture, and were able to hold their shapes on a spoon (Figure 1). The SRD samples were according to guidelines from the National Dysphagia Diet (Level 1: Dysphagia pureed) [10]. The shear stress $(\sigma)$ versus shear rate $\left(\gamma^{\circ}\right)$ data at $25^{\circ} \mathrm{C}$ were well fitted to the power law model (Eq.1) with high determination coefficients $\left(\mathrm{R}^{2}=0.94-1.00\right)$. All SRD samples showed high shear-thinning behavior (they exhibited a reduction in viscosity with increasing shear rate) [21] with flow behavior index (n) values as low as $0.18-0.21$. The $n$ values decreased with increasing concentration of XG.

The magnitude of apparent viscosity $\left(\eta_{\mathrm{a}}, 50\right)$ and consistency index $(\mathrm{K})$ increased with increasing concentration of XG from 0.75 to $1.25 \%$, whereas the apparent viscosity $\left(\eta_{\mathrm{a}}, 50\right)$ decreased with increasing shear rate. The apparent viscosities of SRD samples ranged between 5.13 to $7.07 \mathrm{~Pa} \cdot \mathrm{s}$ (Table 1). It is important to know the suitable viscosity of a puree diet for safe swallowing by an individual with dysphagia. Casanovas et al. [22] obtained similar results of commercial puree diet for dysphagia, ranging between 4.9 to $7.7 \mathrm{~Pa} \cdot \mathrm{s}$ (shear rate $50 \mathrm{~s}^{-1}$ ). From these results, it was found that the rheological behaviors of SRD were dependent on the concentration of XG.

Moreover, XG solutions at low concentration showed a high viscosity when compared with other polysaccharide solutions. Thus, XG was an effective thickener and stabilizer to modify texture of SRD [13].

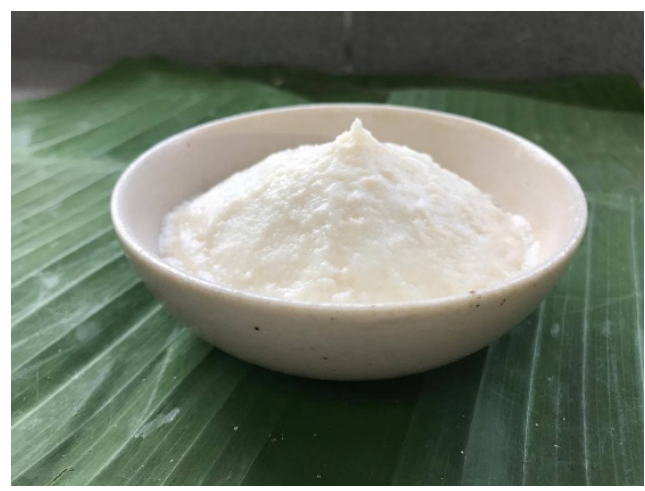

Figure 1 Sweet sticky rice puree diet. 
http://wjst.wu.ac.th

Table 1 Apparent viscosity $\left(\eta_{\mathrm{a}, 50}\right)$, flow behaviour index (n) values, and consistency index (K) of sweet sticky rice puree diet, determined from power law model ${ }^{1}$.

\begin{tabular}{ccccc}
\hline \multirow{2}{*}{ XG (\%) } & ${ }^{2}$ Apparent viscosity & \multicolumn{3}{c}{ Power law } \\
\cline { 3 - 5 } & $\boldsymbol{\eta}_{\mathrm{a}, \mathbf{5 0}}(\mathbf{P a} \cdot \mathbf{s})$ & $\mathbf{n}$ & $\mathbf{K}_{\left(\mathbf{P a} \cdot \mathbf{s}^{\mathbf{n}}\right)}$ & $\mathbf{R}^{\mathbf{2}}$ \\
\hline 0.75 & $5.13 \pm 0.38^{\mathrm{c}}$ & $0.21 \pm 0.02$ & $114.53 \pm 10.25^{\mathrm{b}}$ & 0.97 \\
1.00 & $6.07 \pm 0.21^{\mathrm{b}}$ & $0.21 \pm 0.01$ & $134.57 \pm 3.38^{\mathrm{b}}$ & 1.00 \\
1.25 & $7.07 \pm 0.70^{\mathrm{a}}$ & $0.18 \pm 0.03$ & $184.07 \pm 14.71^{\mathrm{a}}$ & 0.94 \\
\hline
\end{tabular}

${ }^{\mathrm{ab}}$ Means followed by different letters within the same column are significantly different $(\mathrm{p} \leq 0.05)$.

${ }^{1} \sigma=\mathrm{K} \gamma^{\mathrm{n}}$

${ }^{2}$ Apparent viscosity of sticky rice puree diet was measured with shear rate $50 \mathrm{~s}^{-1}$ at $25^{\circ} \mathrm{C}$

\section{Sensory properties}

The concentration of XG had no significant effect on the scores for texture, color, flavor, taste or overall acceptability $(\mathrm{p}>0.05)$ (Table 2). Therefore, the concentration of XG did not affect these sensory parameters. However, the concentration of XG had significant effect on the difficulty of swallowing score (Table 3) ( $\mathrm{p} \leq 0.05)$, which was identified by elderly panelists with dysphagia. The SRD with $0.75 \%$ XG was the easiest to swallow for elderly with dysphagia. Therefore, selecting the appropriate concentration of XG is essential for the modification of SRD texture for elderly with dysphagia. The texture of all SRD samples was easy to swallow, because they obtained "like very much" in the texture scores. This was probably due to pseudoplastic behaviors of XG enhanced sensory qualities of the products [23]. Yoshimura et al. [24] reported that minced foods with XG for elderly foods was sticky, easy to swallow, easy to eat, and better in taste than those without $\mathrm{XG}$.

Table 2 Sensory attribute scores of sweet sticky rice puree diet with different levels of xanthan gum.

\begin{tabular}{lccc}
\hline \multirow{2}{*}{ Attributes } & \multicolumn{3}{c}{ XG (\%) } \\
\cline { 2 - 4 } & $\mathbf{0 . 7 5}$ & $\mathbf{1 . 0 0}$ & $\mathbf{1 . 2 5}$ \\
\hline Texture & $8.50 \pm 0.51$ & $8.50 \pm 0.61$ & $8.45 \pm 0.60$ \\
Color & $8.05 \pm 0.83$ & $8.05 \pm 0.83$ & $8.00 \pm 0.92$ \\
Flavor & $7.55 \pm 1.39$ & $7.65 \pm 1.27$ & $7.55 \pm 1.43$ \\
Taste & $6.65 \pm 1.98$ & $6.80 \pm 1.67$ & $6.10 \pm 1.91$ \\
Overall acceptability & $7.60 \pm 0.94$ & $7.65 \pm 0.88$ & $7.35 \pm 1.14$ \\
\hline
\end{tabular}

Nine-point hedonic scale $(9=$ like very much, $5=$ neither like nor dislike, $1=$ dislike very much $)$

Table 3 Ranking scores of difficulty in swallowing of sweet sticky rice puree diet with different levels of xanthan gum.

\begin{tabular}{rccc}
\hline \multirow{2}{*}{ Attribute } & \multicolumn{3}{c}{ XG (\%) } \\
\cline { 2 - 4 } & $\mathbf{0 . 7 5}$ & $\mathbf{1 . 0 0}$ & $\mathbf{1 . 2 5}$ \\
\hline Difficulty in swallowing & $1.55 \pm 0.69^{\mathrm{a}}$ & $2.15 \pm 0.67^{\mathrm{b}}$ & $2.35 \pm 0.88^{\mathrm{b}}$ \\
\hline
\end{tabular}

${ }^{a b}$ Means followed by different letters within the same row are significantly different $(\mathrm{p} \leq 0.05)$. 


\section{Total phenolic content and antioxidant activities}

Total phenolic content and antioxidant activities by DPPH, FRAP, and ORAC of SRD samples were significantly increased with increasing concentrations of $\mathrm{XG}(\mathrm{p} \leq 0.05)$ (Figure 2). The SRD with $1.25 \%$ XG showed the highest TPC and antioxidant activities. The TPC and antioxidant activities by DPPH, FRAP, and ORAC were $34.50 \mathrm{mg} \mathrm{GAE} / 100 \mathrm{~g}, 67.82,101.75$, and $865.73 \mu \mathrm{mol} \mathrm{TE} / 100 \mathrm{~g}$, respectively. This is probably due to the chemical structure of $\mathrm{XG}$, which consists of hydroxyl groups. It is known that polysaccharides have active hydroxyl groups, which may participate in eliminating free radicals and contribute to antioxidant activity [25]. After degradation, XG showed good water solubility and, hence, exhibited significant antioxidant activity [26]. This is probably because its active hydroxyl groups are more present. Munir et al. [27] also reported that purified XG exhibited TPC was $22.43 \mu \mathrm{g} / \mathrm{mL}$ GAE and antioxidant activity by DPPH was $68.19 \%$, and ascorbic acid was used as standard $(84.12 \%$ antioxidant activity). Their results confirmed that $\mathrm{XG}$ is a source of antioxidants. Shimada et al. [28] also reported that $\mathrm{XG}$ contributes to the inactivation of $\mathrm{Fe}^{2+}$ ions by chelation and inhibits the induced oxidation of soybean oil in the emulsion.

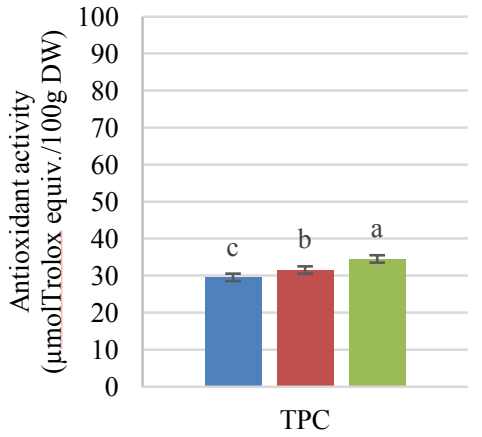

(a)

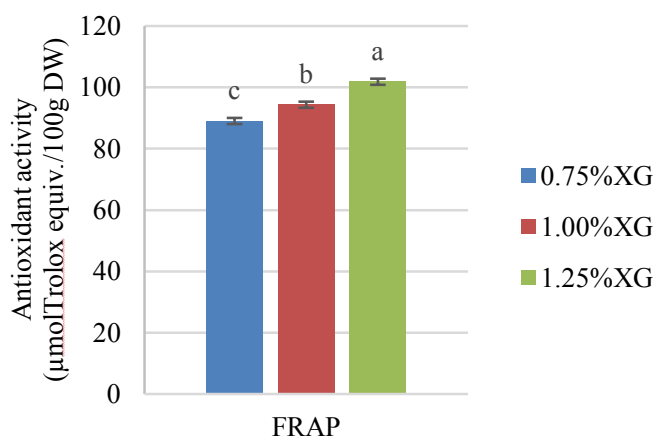

(c)

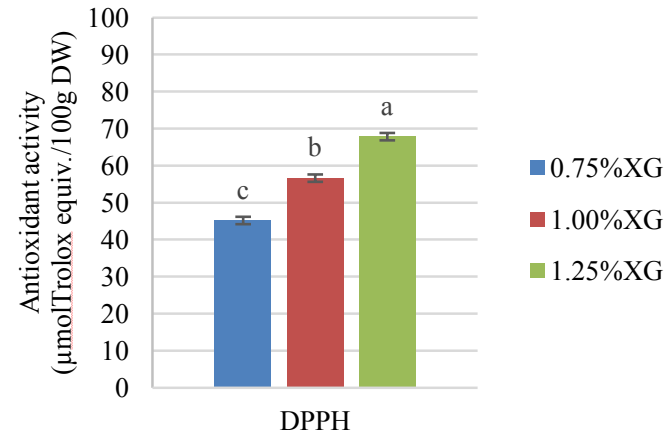

(b)

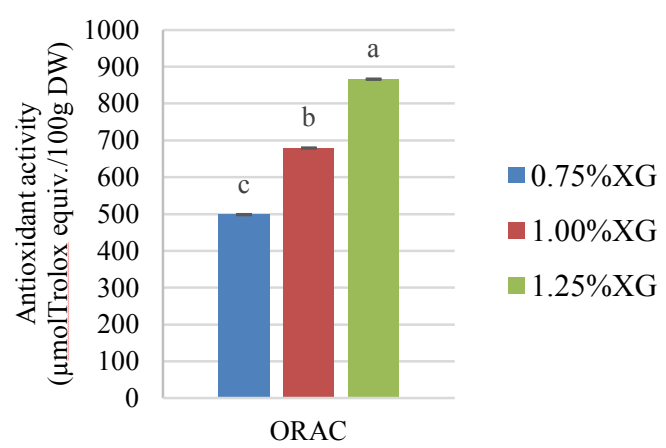

(d)

Figure 2 Effect of xanthan gum on total phenolic content (a) and antioxidant activities \{DPPH (b), FRAP (c) and ORAC (d) $\}$ of SRD. 


\section{Conclusions}

The SRD with $0.75 \%$ XG was selected to be further developed, because the texture was suitable and safe to swallow for elderly with dysphagia. Therefore, puree diets should be prepared with the appropriate concentration of thickeners, because thickeners have different rheological properties depending on their types and concentrations. In addition, total phenolic content and antioxidant activities (DPPH, FRAP, and ORAC) of SRD with $0.75 \% \mathrm{XG}$ were $29.52 \mathrm{mgGAE} / 100 \mathrm{~g}, 45.16,88.96$, and 497.87 $\mu \mathrm{mol} \mathrm{TE} / 100 \mathrm{~g}$, respectively. This puree diet will improve swallowing safety and can be used for the management and treatment of the elderly with dysphagia. Other Thai cuisines should be modified texture for pureed diet use. Thus, there will be more varieties of this kind of product for dysphagia patients.

\section{Acknowledgements}

This research was granted by The Thailand Research Fund-Research and Researcher for Industry (RRi) year 2015 and 4Care Co., Ltd.

\section{References}

[1] United Nations. World Population Aging 2015. Department of Economic and Social Affairs, Population Division, New York, 2015, p. 9-27.

[2] Ministry of Social Development and Human Security. Thai elderly population: Present and Future (in Thai), Available at: https://www.m-society.go.th/article_attach/13225/17347.pdf, accessed March 2017.

[3] Foundation of Thai Gerontology Research and Development Institute. Situation of the Thai elderly 2010 (in Thai), Available at: http://www.thaitgri.org/images/document/ElderSituations/ situationofthailandelderThai2553.pdf, accessed March 2017.

[4] GR Boss and JE Seegmiller. Age-related physiological changes and their clinical significance. West. J. Med. 1981; 135, 434-40.

[5] AWG Walls. Mastication, Nutrition, Oral Health and Health in Older Patients. In: IB Lamster and ME Northridge (eds.). Improving Oral Health for the Elderly: An Interdisciplinary Approach. Springer New York, 2008, p. 353-67.

[6] National Food Institute. The 2013 survey on food consumption behaviors of Thai elderly (in Thai), Available at: http://www.nfi.or.th, accessed March 2017.

[7] IA Humbert and J Robbins. Dysphagia in the elderly. Phys. Med. Rehabil. Clin. N. Am. 2008; 19, $853-65$.

[8] L Sura, A Madhavan, G Carnaby and MA Crary. Dysphagia in the elderly: Management and nutritional considerations. Clin. Interv. Aging 2012; 7, 287-98.

[9] Dietitians Association of Australia and The Speech Pathology Association of Australia Limited. Texture-modified foods and thickened fluids as used for individuals with dysphagia: Australian standardised labels and definitions. Nutr. Diet. 2007; 64, 53-76.

[10] JA Cichero, C Steele, J Duivestein, P Clavé, J Chen, J Kayashita, R Dantas, C Lecko, R Speyer, P Lam and $J$ Murray. The need for international terminology and definitions for texture-modified foods and thickened liquids used in dysphagia management: Foundations of a global initiative. Curr. Phys. Med. Rehabil. Rep. 2013; 1, 280-91.

[11] H Habibi and K Khosravi-Darani. Effective variables on production and structure of xanthan gum and its food applications: A review. Biocatal. Agr. Biotechnol. 2017; 10: 130-40.

[12] S Riso, G Baj and FD Andrea. Thickened beverages for dysphagic patients. Data and myth. Med. J. Nutrition Metab. 2008; 1, 15-7.

[13] BR Sharma, L Naresh, NC Dhuldhoya, SU Merchant and UC Merchant. Xanthan gum: A boon to food industry. Food Promot. Chron. 2006; 1, 27-30.

[14] S Rosalam and R England. Review of xanthan gum production from unmodified starches by Xanthomonas comprestris sp. Enzyme. Microb. Tech. 2006; 39, 197-207. 
http://wjst.wu.ac.th

[15] C Amico, T Tornetta, C Scifo and AR Blanco. Antioxidant effect of $0.2 \%$ xanthan gum in ocular surface corneal epithelial cells. Curr. Eye Res. 2015; 40, 72-6.

[16] K Kawashima, Y Motohashi and I Fujishima. Prevalence of dysphagia among community-dwelling elderly individuals as estimated using a questionnaire for dysphagia screening. Dysphagia 2004; 19, 266-71.

[17] R Amarowicz, RB Pegg, P Rahimi-Moghaddam, B Barl and JA Weil. Free-radical scavenging capacity and antioxidant activity of selected plant species from the Canadian prairies. Food Chem. 2004; 84, 551-62.

[18] LR Fukumoto and G Mazza. Assessing antioxidant and prooxidant activities of phenolic compounds. J. Agr. Food Chem. 2000; 48, 3597-604.

[19] IFF Benzie and JJ Strain. The ferric reducing ability of plasma (FRAP) as a measure of 'Antioxidant Power': The FRAP assay. Anal. Biochem. 1996; 239, 70-6.

[20] B Ou, M Hampsch-Woodill and RL Prior. Development and validation of an improved oxygen radical absorbance capacity assay using fluorescein as the fluorescent probe. J. Agr. Food Chem. 2001; 49, 4619-26.

[21] L Zhong, M Oostrom, MJ Truex, VR Vermeul and JE Szecsody. Rheological behavior of xanthan gum solution related to shear thinning fluid delivery for subsurface remediation. J. Hazard. Mater. 2013; 244-245, 160-70.

[22] A Casanovas, MJ Hernández, E Martí-Bonmatí and M Dolz. Cluster classification of dysphagiaoriented products considering flow, thixotropy and oscillatory testing. Food Hydrocoll. 2011; 25, 851-9.

[23] A Palaniraj and V Jayaraman. Production, recovery and applications of xanthan gum by Xanthomonas campestris. J. Food Eng. 2011; 106, 1-12.

[24] M Yoshimura, T Kuwano, R Morisaki and K Nishinari. Rheological properties and sensory evaluation of the minced foods with xanthan gum. J. Jpn. Soc. Masticat. Sci. Health Promot. 2004; 14, 50-61.

[25] XQ Zha, JH Wang, XF Yang, H Liang, LL Zhao, SH Bao, JP Lua, YY Xu and BB Zhao. Antioxidant properties of polysaccharide fractions with different molecular mass extracted with hotwater from rice bran. Carbohydr. Polym. 2009; 78, 570-5.

[26] X Xiong, M Li, J Xie, Q Jin, B Xue and T Sun. Antioxidant activity of xanthan oligosaccharides prepared by different degradation methods. Carbohydr. Polym. 2013; 92, 1166-71.

[27] M Munir, M Shahid, H Munir, S Javaid, S Sharif and EG Ahmed. Xanthan gum biochemical profiling, antioxidant, antibacterial, biofilm inhibition and mutagenic potential. Curr. Sci. 2017; 114, 1903-13.

[28] K Shimada, H Muta, Y Nakamura, H Okada, K Matsuo, S Yoshioka, T Matsudaira and T Nakamura. Iron-binding property and antioxidative activity of xanthan on the autoxidation of soybean oil in emulsion. J. Agr. Food Chem. 1994; 42, 1607-11. 